\title{
Is Stock Prices and Economic Activity in India Co-Integrated?
}

\author{
G. P. Girish*, S. Vijayalakshmi \\ Department of Finance, IBS Hyderabad, IFHE University, Hyderabad, India \\ Email: "gpgirish.ibs@gmail.com
}

Received 30 March 2016; accepted 24 April 2016; published 27 April 2016

Copyright (C) 2016 by authors and Scientific Research Publishing Inc.

This work is licensed under the Creative Commons Attribution International License (CC BY). http://creativecommons.org/licenses/by/4.0/

(c) (i) Open Access

\begin{abstract}
In this study we investigate whether stock prices and economic activity in India are co-integrated by using monthly data from 1960 to 2013 and applying high-powered co-integration tests which have an inherent advantage of permitting structural changes in the relationships being tested and in asymmetric co-integration, along with frequently applied co-integration tests of Engle and Granger (1987) and Johansen (1988). The results of the study provide empirical evidence for reasonably saying that stock prices and economic activity in India are co-integrated and validate the prediction in financial economics literature.
\end{abstract}

\section{Keywords}

Stock Prices, India, IIP, Co-Integration, Industrial Production

\section{Introduction}

In the last few years, India has been a bright spot in the pecking order of world economies and has been one of the fastest-growing economies in the world. Indian economy is $11^{\text {th }}$ largest based on Nominal GDP terms and $3^{\text {rd }}$ largest in terms of purchasing power parity terms according to International Monetary Fund. Stock markets and financial markets in India have performed remarkably well and have successfully engulfed the imagination and attention of both Indian domestic investors as well as foreign international investors. The co-movements of stock market prices with respect to industrial production (IIP) are enormously imperative for investors for making investment decisions and for policy makers to take a call on monetary policy. Relationship between stock prices and industrial production is crucial and critical from policy makers, investors and businesses' perspective.

In this study we investigate whether stock prices and economic activity in India are co-integrated. In order to determine existence of long-term equilibrium among macro-economic variables, [1] and [2] have proposed co-

${ }^{*}$ Corresponding author. 
integration analysis. The most frequently applied co-integration tests in literature are that of [3] and [4]. However, these tests are outmanoeuvred by high-powered co-integration tests which have an inherent advantage of permitting structural changes in the relationships being tested and in asymmetric co-integration. This is one of those few studies in literature which tries to address whether stock prices and economic activity in India are cointegrated by using monthly data from 1960 to 2013 and applying high-powered co-integration tests.

The results of the study provide empirical evidence to the fact that stock prices and economic activity in India are co-integrated and validate the prediction in financial economics literature from Indian context. The empirical findings of our study contradict results by [5] and [6] who did not find empirical evidence that stock prices and economic activity are co-integrated for US which is surprising to say the least. With a longer span of data from 1961-2013, we have taken cognizance of concerns raised by [7] who argued that span of data used for co-integration tests is vital for power of co-integration tests. The rest of the paper proceeds as follows. In Section 2 we review the literature and discuss alternative co-integration tests which are useful in investigating whether stock prices and economic activity in India are co-integrated in Section 3. In Section 4 we discuss the data considered and present our empirical findings based on application of co-integration tests described in previous section and conclude our study in Section 5.

\section{Literature Review}

In literature we have studies analyzing relationships between financial and macroeconomic variables more specifically stock market returns and macroeconomic variables by [5] [8] and [9] while others have investigated possible long-run relationships between stock market prices and macro-economic variables like [5] and [6] [10]. In order to determine existence of long-term equilibrium among macro-economic variables, [1] and [2] have proposed co-integration analysis. The most frequently applied co-integration tests in literature are that of [3] and [4]. However, these tests are outmanoeuvred by high-powered co-integration tests which have an inherent advantage of permitting structural changes in the relationships being tested and in asymmetric co-integration.

[11] in their study investigated the relationship between stock market and aggregate economy for Mexican economy. [12] in their study found that there exists long-run relationships between Bombay Stock Exchange's SENSEX and industrial production index in India. [13] in their study investigated the relationship between stock prices and industrial production for South Euro-zone and North of Euro-zone for the time period 2004 to 2013 and provided directions for policy makers especially for South of Euro-zone. [14] in their study analysed relationship between industrial production, money supply, inflation, exchange rate, oil prices, and global stock prices with respect to Saudi stock market. [15] in their study found that Ireland's industrial production has a positive impact on economic growth (industrial production).

[16] in their study tried to find out whether Chinese domestic macroeconomic variables can explain Chinese stock market price fluctuations and found out that Industrial production and exports plays a significant role. [17] investigate the role of monetary aggregates including exchange rates as well as industrial production and its relationship with Bangladeshi Stock market (Dhaka Stock Exchange) returns and found out that there exists informational inefficiency in the market. [18] in their study found that money supply, consumer price index, interest rate and industrial production had a significant relationship with Thai Stock Exchange prices.

In this study we employ a few such techniques namely [19]-[21]. Asymmetric co-integration tests of TAR and MTAR with critical values drawn from [22] has also been conducted. The underlying hypothesis of the study is existence of co-integrating relationship between economic activity and stock prices. Literature has found evidence that stock prices are positively related to GDP or IIP which is a proxy for future level of real activity in any economy an off-shoot wile examining marketing efficiency ([5] [6] [23]-[26]). The rationale for this seems to be a common understanding that future stock returns is a function of performance in future. In such a backdrop, it makes logical sense to deem stock market prices/returns act in response to the current state of the economy. In this study we investigate whether stock prices and economic activity in India are co-integrated.

\section{Co-Integration Tests}

The Engle-Granger test [3] is one of the most generally betrothed single equation method for analysing co-integration in econometrics literature. Given 2 variables $x_{t}$ and $y_{t}$ for which co-integrating relationship is being analyzed, first step of EG test involves estimation of static co-integrating regression as given in Equation (1) where the deterministic trend is given by $d_{t}$ which can comprise of an intercept $\left(d_{t}=\alpha\right)$; or linear trend 
with intercept $\left(d_{t}=\alpha+\beta t\right)$ :

$$
y_{t}=d_{t}+\beta x_{t}+\epsilon_{t}, t=1,2, \cdots, T
$$

The next stage involves analyzing order of integration of residuals $\widehat{\epsilon_{t}}$ obtained from potential co-integration relationship between the considered variables $x_{t}$ and $y_{t}$ using Dickey and Fuller test [27] as given in Equation (2). The null hypothesis being examined is that of no co-integration by using t-test statistic for $(\rho-1)$. We augment Equation (2) as obligated by including lagged values of dependent variable.

$$
\Delta \widehat{\epsilon_{t}}=(\rho-1) \widehat{\epsilon_{t-1}}+\vartheta_{t}
$$

Basing on vector error correction model (VECM) frameworks as given in Equation (3), Johansen [4] approach can be employed for analyzing co-integration relationship. $Z_{t}$ is the vector containing I (1) variables which is being investigated and $\pi, \tau_{i}$ represent coefficient matrices. Eigen values of long-run coefficient matrix $\pi$ using maximal and trace eigen value test statistic helps in analyzing the extent of co-integration existing between the considered variables. Terms which need to be included in VAR and co-integrating term of Equation (3) is very crucial while empirically applying Johansen's procedure.

$$
\Delta Z_{t}=\sum_{i=1}^{k-1} \tau_{i} \Delta Z_{t-i}+\pi Z_{t-k}+v_{t}
$$

Kanioura and Turner's [20] study provides an alternative higher-powered when compared to EG test. F-test of [20] is based on significance of lagged level terms in the below mentioned error correction model (ECM) as given in Equation (4). Null hypothesis considered is $H_{0}: \alpha_{2}=\alpha_{3}=0$. Similar to previous discussed tests of cointegration, empirical application of Kanioura and Turner's [20] F test requires inclusion of lagged values of dependent variables in-order to circumvent issues of serial correlation.

$$
\Delta y_{t}=\alpha_{0}+\alpha_{1} \Delta x_{t}+\alpha_{2} y_{t-1}+\alpha_{3} x_{t-1}+\varepsilon_{t}
$$

Monte Carlo analysis as presented by [28] highlight that power of Engle-Granger test substantially reduces when EG test is applied to a series which is co-integrated. To combat this, [21] broaden Engle-Granger test for explicitly allowing breaks in either intercept or intercept and co-integrating coefficient at unknown point of time. The Equation (1) used in Engle-Granger test is modified as given below in Equation (4) for the following three models:

$$
\begin{aligned}
& \text { Model C: Level shift } y_{t}=\mu_{0}+\mu_{1} \varphi_{t}+\alpha x_{t}+\omega_{t} \\
& \text { Model C/T: Level shift with trend } y_{t}=\mu_{0}+\mu_{1} \varphi_{t}+\beta t+\alpha x_{t}+\omega_{t} \\
& \text { Model C/S: Regime Shift } y_{t}=\mu_{0}+\mu_{1} \varphi_{t}+\alpha_{1} x_{t}+\alpha_{2} \varphi_{t} x_{t}+\omega_{t}
\end{aligned}
$$

All the three Models of Equation (5) allow structural change via $\varphi_{t}$ which is the dummy variable. $\varphi_{t}$ is defined as follows:

$$
\varphi_{t}= \begin{cases}1 & \text { if } t>\tau \\ 0 & \text { otherwise }\end{cases}
$$

$\tau$ denotes the juncture where the break in sample occurs. [21] suggest grid search technique for determining the value of $\tau$ by taking into consideration all values in middle $70 \%$ of sample being considered. For each value of $\tau$, Equation (5) models are estimated and residuals are extracted $\widehat{\omega}_{t}$ which is used in Equation (6)'s Dickey-Fuller test as given below which may be augmented as deemed necessary by incorporation of lagged values of $\Delta \widehat{\omega}_{t}$. The test statistic obtained for each of the three models is further given as minimum value obtained for t-ratio of $(\rho-1)$.

$$
\Delta \widehat{\omega_{t}}=(\rho-1) \widehat{\omega_{t}}+\vartheta_{t}
$$

Engle-Granger test of Equation (2) make a tacit underlying assumption of symmetry implying a single speed of adjustment to equilibrium which is extended by [22] by permitting differing speeds of adjustment to take place. With the basis of TAR method given by [29] and [30], he Equation (2) used in EG test are extended by using Heaviside indicator function $I_{t}$ as below with necessary augmentation incorporated: 


$$
\Delta \widehat{\epsilon_{t}}=I_{t} \rho_{1} \widehat{\epsilon_{t-1}}+\left(1-I_{t}\right) \rho_{2} \widehat{\epsilon_{t-1}}+\varepsilon_{t}
$$

The Heaviside indicator functions $I_{t}$ as proposed by [22] for TAR and MTAR co-integration tests are given below:

$$
\begin{gathered}
I_{t}= \begin{cases}1 & \text { if } \widehat{\epsilon_{t-1}} \geq \tau \\
0 & \text { if } \widehat{\epsilon_{t-1}}<\tau\end{cases} \\
I_{t}= \begin{cases}1 & \text { if } \widehat{\Delta \epsilon_{t-1}} \geq \tau \\
0 & \text { if } \widehat{\Delta \epsilon_{t-1}}<\tau\end{cases}
\end{gathered}
$$

Null hypothesis of no co-integration is examined under both TAR and MTAR specification by employing joint hypothesis of $H_{0}: \rho_{1}=\rho_{2}=0$. Statistically significant difference in the asymmetric adjustment coefficients i.e. $\rho_{1}$ and $\rho_{2}$ indicates existence of long-run relationship but the reversion occurs at differing speeds owing to the indicator function used.

\section{Empirical Findings}

Relationship between Stock Prices and Industrial Production is crucial and critical from Policy makers, Investors and businesses perspective. In this study we investigate whether stock prices and economic activity are co-integrated for India. We use monthly data extracted from Bloomberg database from January 1960 to July 2013 for stock prices of Bombay Stock Exchange (BSE) of India and industrial production (IIP). Natural logarithmic is applied for both stock prices and IIP time-series. Investigation of presence of unit root test to the series shows that both the series are not stationary at level however the series become stationary after first difference as given in the Unit root test results of Table 1 implying both stock prices and IIP series are I (1) processes. Impending co-integration between the two series is examined by applying co-integration tests discussed in previous section and the results are presented in Table 2 and Table 3.

As seen from Table 2, Engle and Granger test fails to reject null hypothesis of no co-integration between both the series at 5\% critical value level for both the conditions of considering only intercept or intercept and trend. It has been found that the calculated test statistics of -3.197909 and -3.161978 are not sufficiently large enough in absolute terms to reject the null hypothesis against 5\% critical values of 0.0717 and 0.2018 according to EG test. The degree of augmentation for EG was determined using Akaike's Information Criterion under the condition that there is no serial correlation by using LM test. The results for [19] is similar to the one obtained for EG test. The results for Johansen's procedure using VAR lead to rejection of null hypothesis of no co-integration between the series for India with maximum Eigen value and trace test statistic of 38.81014 and 46.55772 overshadowing the 5\% critical values of 19.38704 and 25.87211 respectively.

Calculated statistic for higher-powered co-integration test of Kanioura and Turner's (2005) 4.735876 fails to surpass the $5 \%$ critical value of 5.83. We followed a similar approach for the other residual-based tests and for Kanioura and Turner (2005)'s F-test and in all cases a lag length of zero was found. Based on the results of Gregory-Hansen test for any of the Models (C, C/T, C/S), we cannot reject the null hypothesis of no co integration. It appears that failure of EG and Phillips-Ouliaris tests to detect co-integration between stock prices and industrial production may not be due to lack of power of the co-integration test. Testimony to this fact is that higher-powered Kanioura and Turner (2005)'s F-test also leads to similar conclusion. To scrutinize whether no co-integration is due to utilization of inappropriate alternative hypothesis, our analysis is extended to authorize possibilities of structural change in the co-integrating relationships and asymmetric adjustment.

\begin{tabular}{ccccc} 
Table 1. Unit root results. & \multicolumn{3}{c}{ First difference } \\
\hline \multirow{2}{*}{ Series } & LDF & KPSS & ADF & KPSS \\
\cline { 2 - 5 } & -2.171115 & $0.591386^{* * *}$ & $-6.182248^{* * *}$ & 0.052444 \\
IIP & -2.636801 & $0.386570^{* * *}$ & $-16.44410^{* * *}$ & 0.083549 \\
SP & & & &
\end{tabular}

Note: Significance at the $1 \%$ level. 
Table 2. Co-integration test results.

\begin{tabular}{ccc}
\hline Test & Calculated test statistic & 5\% critical value \\
\hline Engle and Granger & & \\
$d_{t}=\alpha$ & -3.197909 & 0.0717 \\
$d_{t}=\alpha+\beta t$ & -3.161978 & 0.2018 \\
Phillips-Ouliaris (1990) & & 0.0345 \\
$d_{t}=\alpha$ & -3.488888 & 0.0448 \\
$d_{t}=\alpha+\beta t$ & -3.837277 & \\
Johansen & & 19.38704 \\
Maximum Eigen Value & 38.81014 & 25.87211 \\
Trace & 46.55772 & 5.83 \\
Kanioura and Turner (2005) F-test & 4.735876 & \\
Gregory-Hansen & & -4.61 \\
Model C & -4.23 & -5.50 \\
Model C/T & -4.11 & -4.95 \\
Model C/S & -4.21 & \\
\hline
\end{tabular}

Note: The tabulated test statistics and critical values for alternative co-integration tests have been calculated as discussed in Section 3. The critical values for the EG, Johansen, F-test and Gregory-Hansen tests have been drawn from [5] [20] [21] [31]-[33].

Table 3. Asymmetric co-integration tests for de-trended series.

\begin{tabular}{cc} 
TAR & \\
\hline$\rho_{1}, \rho_{2}$ & $-0.02928,-0.0789$ \\
$\rho_{1}=\rho_{2}=0$ & 8.75189 \\
$5 \%$ critical value & 6.93 \\
\hline MTAR & $-0.00145,-0.05922$ \\
$\rho_{1}, \rho_{2}$ & 8.13974 \\
$\rho_{1}=\rho_{2}=0$ & 6.62 \\
$5 \%$ critical value & 8.62 \\
\hline
\end{tabular}

Note: The tabulated test statistics and critical values for TAR and MTAR co-integration tests been calculated as discussed in Section 3. The critical values are drawn from [5] [21].

Table 3 presents results from asymmetric co-integration tests. TAR model shows adjustment parameters $\rho_{1}$ $\rho_{2}$ to take on different values. These calculated values are indicative of asymmetric co-integration between thẻ two series. Comparing calculated and critical values leads to rejection of null at $5 \%$ critical value. We find similar findings for MTAR-based co-integration test with the calculated statistic being higher than the 5\% critical value leading to rejection of null hypothesis that there is no co-integration.

The results of Engle and Granger test, Phillips-Ouliaris test, Kanioura and Turner's test and Gregory-Hansen test leads to the conclusion that stock prices and industrial production in India are not co-integrated. However, Johansen's co-integration test based on maximum Eigen value and trace statistic lead to a conclusion that stock prices and industrial production in India are co-integrated. Asymmetric Co-integration Tests for de-trended series using TAR and MTAR lead to the conclusion that there exists co-integration between stock prices and industrial production (IIP) for India.

\section{Conclusion}

The relationship between stock prices and industrial production is crucial and critical from policy makers, investors and businesses' perspective. In this study we investigated whether stock prices and economic activity in India are co-integrated by using monthly data from 1960 to 2013. In order to determine existence of long-term equilibrium among macro-economic variables, we applied high-powered co-integration tests which have an in- 
herent advantage of permitting structural changes in the relationships being tested and in asymmetric co-integration by employing Engle and Granger's test, Phillips-Ouliaris test, Kanioura and Turner's test, GregoryHansen's test and asymmetric co-integration tests of TAR and MTAR with critical values drawn from Enders and Siklos. Though we get mixed results, based on empirical evidence of Johansen's test and Asymmetric Cointegration test results for de-trended series using TAR and MTAR, we can reasonably say that stock prices and economic activity in India are co-integrated and validate the prediction in financial economics literature from Indian context.

\section{References}

[1] Granger, C.W.J. and Escribano, A. (1986) Limitation on the Long-Run Relationship between Prices from an Efficient Market. UCSD Discussion Paper.

[2] Johansen, S. and Juselius, K. (1990) Maximum Likelihood Estimation and Inference on Cointegration, with Applications to the Demand for Money. Oxford Bulletin of Economics and Statistics, 52, 169-210. http://dx.doi.org/10.1111/j.1468-0084.1990.mp52002003.x

[3] Engle, R. and Granger, C. (1987) Cointegration and Error Correction: Representation, Estimation and Testing. Econometrica, 55, 251-276. http://dx.doi.org/10.2307/1913236

[4] Johansen, S. (1988) Statistical Analysis of Cointegration Vectors. Journal of Economics Dynamics and Control, 12, 231-254. http://dx.doi.org/10.1016/0165-1889(88)90041-3

[5] Cook, S. (2006) Are Stock Prices and Economic Activity Cointegrated? Evidence from the US, 1950-2005. Annals of Financial Economics, 2, Article ID: 0650003. http://dx.doi.org/10.1142/s2010495206500035

[6] McMillan, G.G. (2005) Time Variation in the Cointegrating Relationship between Stock Prices and Economic Activity. International Review of Applied Economics, 19, 359-368. http://dx.doi.org/10.1080/02692170500119862

[7] Hakkio, C. and Rush, M. (1991) Cointegration: How Long Is the Short Run? Journal of International Money and Finance, 10, 571-581. http://dx.doi.org/10.1016/0261-5606(91)90008-8

[8] Henry, O.N.O. and Thong, J. (2004) Do Stock Market Returns Predict Changes to Output? Evidence from a Nonlinear Panel Data Model. Empirical Economics, 29, 527-540. http://dx.doi.org/10.1007/s00181-003-0182-4

[9] Pesaran, M. and Timmerman, A. (2000) A Recursive Modelling Approach to Predicting UK Stock Returns. Economic Journal, 110, 159-191. http://dx.doi.org/10.1111/1468-0297.00495

[10] Nasseh, A. and Strauss, J. (2000) Stock Prices and Domestic and International Activity: A Cointegration Approach. Quarterly Review of Economics and Statistics, 40, 229-245. http://dx.doi.org/10.1016/s1062-9769(99)00054-x

[11] Ponce, R.A.C. and Acosta, R.J.R. (2008) Economic Integration in North America. Applied Econometrics and International Development, 8, 111-122.

[12] Dasgupta, R. (2012) Long-Run and Short-Run Relationships between BSE SENSEX and Macroeconomic Variables. International Research Journal of Finance and Economics, 95, 135-150.

[13] Tsagkanos, A. and Siriopoulos, C. (2015) Stock Markets and Industrial Production in North and South of Euro-Zone: Asymmetric Effects via Threshold Cointegration Approach. Journal of Economic Asymmetries, 12, 162-172. http://dx.doi.org/10.1016/j.jeca.2015.07.001

[14] Kalyanaraman, L. (2015) Long-Run and Short-Run Relationship between Macroeconomic Factors and Returns on Sectoral Indices in Saudi Arabia: An Empirical Analysis. Mediterranean Journal of Social Sciences, 6, 333-344. http://dx.doi.org/10.5901/mjss.2015.v6n2p333

[15] Adamopoulos, A. (2013) Financial Development and Economic Growth: A Revised Empirical Study for Ireland. European Research Studies Journal, 16, 25-33.

[16] Liang, P. and Willett, T.D. (2015) Chinese Stocks during 2000-2013: Bubbles and Busts or Fundamentals? Chinese Economy, 48, 199-214.

[17] Joarder, M.A.M., Ahmed, M.U., Haque, T. and Hasanuzzaman, S. (2014) An Empirical Testing of Informational Efficiency in Bangladesh Capital Market: Informational Efficiency in Bangladesh Capital Market. Economic Change and Restructuring, 47, 63-87. http://dx.doi.org/10.1007/s10644-013-9142-y

[18] Ato Forson, J. and Janrattanagul, J. (2014) Selected Macroeconomic Variables and Stock Market Movements: Empirical Evidence from Thailand. Contemporary Economics, 8, 157-174.

[19] Phillips, P.C.B. and Ouliaris, S. (1990) Asymptotic Properties of Residual Based Tests for Cointegration. Econometrica, 58, 165-193. http://dx.doi.org/10.2307/2938339

[20] Kanioura, A. and Turner, P. (2005) Critical Values for an F-Test for Cointegration in a Multivariate Model. Applied Economics, 37, 265-270. http://dx.doi.org/10.1080/00036840412331315051 
[21] Gregory, A. and Hansen, B. (1996) Residual-Based Tests for Cointegration in Models with Regime Shifts. Journal of Econometrics, 70, 99-126. http://dx.doi.org/10.1016/0304-4076(69)41685-7

[22] Enders, W. and Siklos, P. (2001) Cointegration and Threshold Adjustment. Journal of Business and Economic Statistics, 19, 166-176. http://dx.doi.org/10.1198/073500101316970395

[23] Fama, E.F. (1990) Stock Returns, Expected Returns, and Real Activity. The Journal of Finance, 45, 1089-1108. http://dx.doi.org/10.1111/j.1540-6261.1990.tb02428.x

[24] Bilson, M.C., Brailsford, T.J. and Hooper, V.J. (2001) Selecting Macroeconomic Variable as Explanatory Factors of Emerging Stock Market Returns. Pacific-Basin Finance Journal, 9, 401-426. http://dx.doi.org/10.1016/S0927-538X(01)00020-8

[25] Girish, G.P. and Rastogi, N. (2013) Efficiency of S\&P CNX Nifty Index Option of the National Stock Exchange (NSE), India, Using Box Spread Arbitrage Strategy. Gadjah Mada International Journal of Business, 15, 269-285.

[26] Singhania, K. and Girish, G.P. (2015) Impact of Macroeconomic Events on Shanghai Stock Exchange. Asian Journal of Empirical Research, 6, 64-76.

[27] Dickey, D. and Fuller, W. (1979) Distribution of the Estimators for Autoregressive Time Series with a Unit Root. Journal of the American Statistical Association, 74, 427-431.

[28] Gregory, A.J.N. and Watt, D. (1996) Testing for Structural Breaks in Cointegrated Relationships. Journal of Econometrics, 71, 321-341. http://dx.doi.org/10.1016/0304-4076(96)84508-8

[29] Tong, H. (1983) Threshold Models in Nonlinear Time-Series Analysis. Springer-Verlag, New York.

[30] Tong, H. (1990) Nonlinear Time-Series: A Dynamical Approach. Oxford University Press, Oxford.

[31] MacKinnon, J. (1991) Critical Values for Cointegration Tests. In: Engle, R. and Granger, C., Eds., Long Run Economic Relationships, Oxford University Press, Oxford, 267-276.

[32] MacKinnon, J.A.H. and Michelis, L. (1999) Numerical Distribution Functions of Likelihood Ratio Tests for Cointegration. Journal of Applied Econometrics, 14, 563-577. http://dx.doi.org/10.1002/(SICI)1099-1255(199909/10)14:5<563::AID-JAE530>3.0.CO;2-R

[33] Perron, P. and Rodriguez, G. (2001) Residual Based Tests for Cointegration with GLS Detrended Data. Econometric Theory. 